part of the participants expresses the need for a booster and trainers are highly motivated to provide it. Therefore, we think it's worthwhile to start experimenting with organizing booster sessions on a small scale and, depending on the outcomes, consider further implementation.

References:

[1] References can be obtained from the first author.

Disclosure of Interest: None declared

DOI: 10.1136/annrheumdis-2017-eular.6171

\section{PARE0015 THE IMPORTANCE OF FACE-TO-FACE NETWORKS: FINDINGS FROM THE 2ND EULAR YOUNG PARE CONFERENCE, "CHANGE THE FUTURE"}

J. Andersen ${ }^{1,2}$, P. Balazova ${ }^{3,4}$, W. Olsder ${ }^{5}$, S. Ostuzzi ${ }^{6}$, D. Papastavrou ${ }^{4,7}$ S. Stones ${ }^{8,9}$, T. Wilhelmer $^{10}$, P. Boyd ${ }^{11}$ on behalf of EULAR Young PARE. ${ }^{1} 5$ sle/Lupus Ung Dk, Gigtforeningen, Gentofte, Denmark, Gentofte, Denmark; ${ }^{2}$ Lupus Europe, Essex, United Kingdom, Essex, United Kingdom; ${ }^{3}$ Slovak League Against Rheumatism, Piestany, Slovakia, Piestany, Slovakia; ${ }^{4}$ EULAR Standing Committee of PARE, Zurich, Switzerland, Zurich, Switzerland: ${ }^{5}$ Youth-R-Well.com, Lisse, The Netherlands, Lisse, Netherlands; ${ }^{6}$ ANMAR Young, Rome, Italy, Rome, Italy; ${ }^{7}$ ELEANA Hellenic League Against Rheumatism, Athens, Greece, Athens, Greece: ${ }^{8}$ School of Healthcare, University of Leeds, Leeds, United Kingdom, Leeds; ${ }^{9}$ Fibromyalgia Action UK, Paisley, Renfrewshire, United Kingdom, Paisley, United Kingdom; ${ }^{10}$ Österreichische Rheumaliga, Salzburg, Austria, Salzburg, Austria; ${ }^{11}$ Arthritis Ireland, Dublin, Ireland, Dublin, Ireland

Background: EULAR Young PARE's strategy for 2020 is to establish and strengthen groups for young people with rheumatic and musculoskeletal diseases (RMDs) across Europe, by developing a collaborative network. We aim to empower youth leaders to ensure the voice of young people with RMDs is heard. To facilitate this, the 2nd EULAR Young PARE Conference was held in Retie, Belgium in October 2016.

Objectives: To empower and educate EULAR Young PARE youth liaisons, focusing on developing academic and interpersonal skills to best support young people across Europe living with RMDs. This was achieved through a series of practical, skills-based workshops and plenary sessions.

Methods: The EULAR Young PARE working group reflected on the conference during a debrief meeting. A post-conference evaluation was completed by liaisons. A five-point Likert scale ( $1=$ very bad, $5=$ very good) was used alongside open questions. In addition, there was an informal meeting to generate discussions and receive input from participants regarding the future direction and focus of EULAR Young PARE in 2017 and 2018.

Results: The conference was attended by 22 youth liaisons from 20 organisations. The programme was well received with the face-to-face interactions favoured to establish and grow collaborative networks. Through a series of digital poster presentations, each liaison had the opportunity to share recent work in their national organisations. This session was evaluated positively and encouraged liaisons to identify opportunities for collaboration and new national activities, using the VKC as a platform for the sharing of best practices. Workshops were delivered in collaboration with EMEUNET and a EULAR member organisation representative and we piloted a series of six walk-in workshops. While these workshops were evaluated positively, a lack of structure and the need for time constraints was a consistent finding.

Conclusions: The "Change the Future" conference was a successful meeting of youth liaisons from across Europe, who were highly satisfied with the programme and mechanism of delivery. Meeting in person facilitated the growth and continued involvement within the EULAR Young PARE network. The activities of EULAR, and specifically the Standing Committee of PARE, were shared with liaisons, encouraging liaisons to become involved in a wider number of EULAR activities. Theoretical and practical skills were developed, while best practices and experiences were shared and highly valued. Furthermore, in future conferences, bitesize workshops will replace walk-in workshops for structure and clarity. Despite living in a digitally connected world, face-to-face interactions cannot be replaced. Learning can be enhanced and actions implemented when motivated individuals are physically united, demonstrating the need for the use of multiple meeting methods to drive innovation. Following the conference, everyone felt inspired, empowered and motivated to implement concrete and tangible steps to inform ongoing and future work. Together, we can change the future for young people living with RMDs.

Disclosure of Interest: None declared

DOI: 10.1136/annrheumdis-2017-eular.3203

\section{PARE0016 KEEP CALM AND TELL ME YOUR STORY!: A NARRATIVE MEDICINE PILOT PROJECT FOR ITALIAN YOUNG PEOPLE LIVING WITH RHEUMATIC AND MUSCULOSKELETAL DISEASES}

U.G. Viora ${ }^{1}$, S. Ostuzzi ${ }^{2,3}$ on behalf of ANMAR Italia - ANMAR Young. ${ }^{1}$ Anmar Italia, Torino; ${ }^{2}$ Anmar Young, Anmar Italia, Rome, Italy; ${ }^{3}$ Eular Young Pare, Zurich, Switzerland

Background: The 7th point of EULAR Young PARE's Youth Strategy states that "By 2020, every European country has an active national youth group for young people with rheumatic and musculoskeletal diseases (RMDs)". On this basis, ANMAR - Italian national association for people with RMDs - has engaged in the creation of a youth group dedicated to Italian young people (aged 18-35) living with RMDs: ANMAR Young was born in 2015, through EULAR's Knowledge Transfer Programme. During its first year of activities, ANMAR Young has launched the pilot project of a narrative medicine campaign called Keep Calm and Tell Me Your Story!

Objectives: Keep Calm and Tell Me Your Story! was designed to make sure that the voice of young Italian people living with RMDs is heard, spread, and listened to. In its pilot phase, the project aimed to consult, engage, involve young rheumatic patients while building an Italian network. A major pilot phase's objective was, as well, the launch of a booklet presenting the collected stories on World Arthritis Day 2016.

Methods: The ANMAR Young task force has drafted the four different writing traces to compose the campaign, investigating some crucial issues, such as: the impact of RMDs on young people's personal life, working life and education; the experience of transitioning from pediatric to adult rheumatology care services; young rheumatic patients' unmet needs and priorities. The criteria for inclusion of participants were deliberately simple: every Italian person living with any RMDs and aged from 18 to 35 could take part in the campaign. Texts have been collected anonymously exclusively through an online form, promoted and disseminated mostly through social media. The pilot project campaign has lasted one month, from the end of July 2016 until the end of August 2016.

Results: From the end of July 2016 to the end of August 201621 stories have been submitted by 20 female respondents and 1 male respondent coming from 11 different Italian regions, suffering from different RMDs (among which the condition reported more often is Juvenile Idiopathic Arthritis). The collection has become the subject of a booklet, published in an edition of about 5,000 copies and officially launched in October 2016 in Rome, on World Arthritis Day. The campaign spread online, allowing ANMAR Young to gather different experiences, expand its network, contribute in the process of empowerment and engagement of Italian young rheumatic patients.

Conclusions: The campaign Keep Calm and Tell Me Your Story! has proved to be a valuable, peer-to-peer, economically sustainable, easily manageable and repeatable (also abroad) engaging tool for raising awareness about the impact of RMDs on the quality of life of young people. We intend to further develop this narrative medicine experience by keeping collecting new stories, by sharing them weekly through social media, by promoting our printed booklet. We intend to further analyze in detail the collected texts, in order to read them not only as personal experiences but also as a qualitative mapping of Italian young people with RMDs' unmet needs and priorities.

Disclosure of Interest: None declared

DOI: 10.1136/annrheumdis-2017-eular.6175

\section{PARE0017 EMPOWERING PATIENTS WITH OSTEOARTHRITIS WITH NON-PHARMACOLOGICAL MEASURES}

J. Vergés ${ }^{1}$, J. Monfort ${ }^{2}$, M. Bibas ${ }^{1}$, M.T. Vergés ${ }^{1} .{ }^{1}$ Osteoarthritis Foundation International; ${ }^{2}$ Hospital del Mar, Barcelona, Spain

Background: Osteoarthritis $(\mathrm{OA})$ and other joint pains are generally seen as ailments that affect people with age. With the increase in life expectancy over recent decades, the prevalence of people with $\mathrm{OA}$ is drastically growing. Estimates suggest that there are $242 \mathrm{M}$ people with $\mathrm{OA}$ in the world ${ }^{1} ; 30 \mathrm{M}$ live in Europe ${ }^{2}$. The most commonly affected joint at the present time is the knee, followed by hips and shoulders ${ }^{3}$.

Objectives: To run an educational program that will provide elderly people with tools to tackle their problems of joints so that they can improve their quality of life by adopting non-pharmacological measures. A well-informed patient knows how to address their disease. Thus, they can improve their quality of life.

Methods: The method is based on the capacity of a motivated patient to positively influence others also worried by their health situation by sharing their experiences and awareness of the disease.

Stage I. Preparatory actions:

1. Elaboration of contents: An expert team (psychologist, nurse, rheumatologist, family doctor, physiotherapist and rehabilitator) elaborates the content: Knowledge, Weight control, Doing the right exercise, Dealing with the disease

2. Engagement of the target group: "La Caixa" Banking Foundation is supporting this study by giving access to its 63 senior centers in Catalonia (Spain)

3. Selection of senior centers: The educational program is planned to be run in 6 centers. Currently, 20 centers are conducting initial presentations to evaluate interest and ensure the selection of 6 final centers

4. Enrollment of smart seniors: 12 people will be selected ( 2 per center), called hereafter, "smart patients", through a survey so we can assess interest of enrolling and quality of the presentation

Stage II. Training and implementation:

5. Training of smart patients: Train selected smart patients during 9 sessions, 90 minutes each

6. Training groups of patients: Every smart patient will train 2 groups of 10 people also interested in joint health. A nurse will be in every session, giving support only if necessary

7. Evaluation and follow-up: Improvement of participants in the course will be assessed (anticipated sample size 240 people) by surveying level of satisfaction 
(ARTS questionnaire), improvement of pain and functionality (WOMAC), improvement in perceived quality of life (EuroQuol 5), improvement of the degree of self-care to achieve a good management of the disease (IC, MPOC and TAC programs), improvement in therapeutic compliance

Results: Stage I initial presentations have been conducted at 8 out of 20 centers in urban and semi-rural areas to account for different social, economic, education and lifestyle demographics. Participants surveyed: 305 ; Interest in being a smart patient: 76; Interest in participating in the program: 193; No interest: 36; Level of satisfaction: $>90 \%$ reporting good or very good.

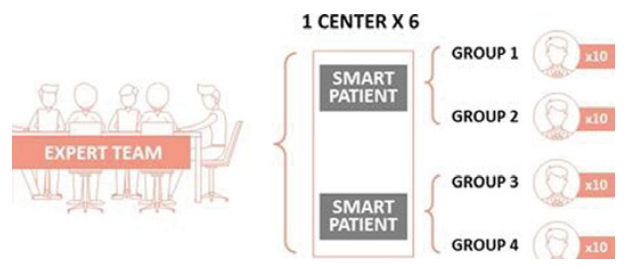

Conclusions: Based on results to date, after the 20 sessions the team expects to collect 763 surveys and identify 190 potential smart patients and 483 people willing to participate in the program. There is a clear interest or concern for OA disease in elderly people and they want to take more responsibility for their disease and age with quality of life.

References:

[1] Global Burden of Disease Study 2013 Collaborators, The lancet, June 8, 2015.

[2] Osteoarthritis - An Overview, Frost \& Sullivan, May 17th 2007.

[3] EPISER STUDY 2001, Spanish Rheumatology Society.

Disclosure of Interest: None declared

DOI: 10.1136/annrheumdis-2017-eular.3180

\section{PARE0018 WE DO THE IMPOSSIBLE, BECAUSE THE POSSIBLE EVERYONE CAN DO WAD AWARENESS CAMPAIGN}

\section{H. Bankova, B. Ivkov, S. Bozhinova, B. Boteva. BOPRD, Sofia, Bulgaria}

Background: One of the main priorities that Bulgarian organization for people with rheumatic diseases follows is dissemination of knowledge and information about RMD'S and their impact on people's life and to the society.

The WAD awareness campaign is the culmination of the organization's activities during the whole year.

Objectives: The main goal of the 2016 WAD awareness campaign was to:

- Inform the society and BOPRD's members about the social importance of RMD's.

- To inform BOPRD's members what are their rights as people with long term chronic condition.

- To inform the society about RMD's and the challenges that people with RMD's face.

- To challenge the people with RMD's to look into their inner world and to define what are their strengths and weaknesses.

- To make the informing process more attractive, by visualizing the key features of life with an RMD.

Methods: In 2016 BOPRD organized an awareness campaign - "We do the impossible, because the possible everyone can do"

The start of our campaign was on 1st of October and lasted for more than two weeks till the World arthritis day and ended on 16th of October. Informative and motivating pictures, with information about different RMD's, were published every day on the official BOPRD's Facebook page and were shared in the closed group for people with rheumatic diseases as well.

A social experiment among the members of the organization was made. They were asked to explain what the disease means to them, like they are telling the story to a person who do not know anything about it.

The aim of this experiment was to identify the meaning and significance which people with rheumatic diseases give to their condition, as well as the basic problems result from the illness.

Based on the social experiment and analysis of 33 small biographical narratives 17 basic characteristics of the rheumatic diseases are identified. These characteristics form the problematic areas for people with RMD's and bases for their study. The main characteristics are life with chronic pain, the process of disabling, life in continuous compliance with the environment and the high degree of uncertainty and ambiguity, imposed by chronic illness.

An e-booklet, containing the results of the social experiment was published on BOPRD's Facebook page and website on 12th October. On the same day we published the WAD video, of the PARE WAD campaign: "The future is in your hands". At the end of the awareness campaign we published an online booklet, which contained translated articles about RMD's and the different aspects of life with a chronic condition.

Results:

- The total number of all publications is 22 .

- The publications were seen from over 3000 people.

- The WAD video was seen by 1000 people.

- The results of the social experiment were seen by 1500 people.

- The most popular were those pictures that managed to touch people's feelings.

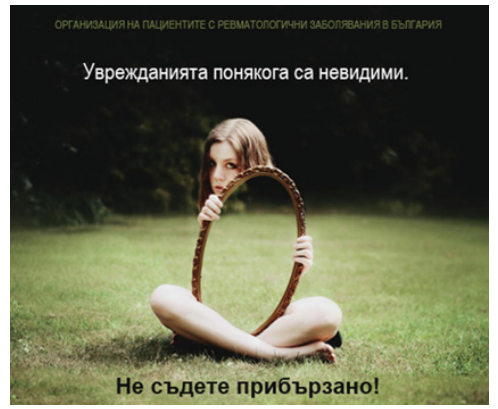

Conclusions: Main common characteristics of rheumatic diseases were identified and can help patients in getting the right diagnosis.

The most popular were the posts that were related to emotions and experience of life with a chronic condition.

By publishing the results of the social experiment we managed to help those who read the narratives get the feeling that they are not alone.

The results of the social experiment will be used as a basis in developing a manual for the main symptoms of RMD's (the patient perspective)

Acknowledgements: Miglena Ivanova

Cveta Apostolova

Disclosure of Interest: None declared

DOI: 10.1136/annrheumdis-2017-eular.3095

\section{PARE0019 ADHERENCE TO THERAPY: A COMPARISON BETWEEN THREE PATIENTS POPULATIONS WITH AUTOIMMUNE INFLAMMATORY DISEASES}

U.G. Viora ${ }^{1}$, R. Giannelli ${ }^{2}$, M.G. Pisu ${ }^{3}$, G. Voltan ${ }^{4}$ on behalf of ANMAR Italia. ${ }^{1}$ Anmar Italia, Torino; ${ }^{2}$ Anmar Italia, Firenze; ${ }^{3}$ Anmar Italia, Milano; ${ }^{4}$ Anmar Italia, Roma, Italy

Background: Non-adherence to therapy is one of the main obstacles achieving the goals of care in chronic autoimmune inflammatory diseases, including Rheumatic diseases (RMDs). In the "MOSAICO" study, ANMAR along with two other associations of Italian patients (AMICI chronic inflammatory bowel diseases (IBD) and ANAP - psoriasis (PSO) and chronic dermatological diseases) wanted to compare the adherence to therapies for IBD, RMDs and PSO and identify key problems that can affect it positively or negatively. This paper presents the results related to adherence to treatment, the obstacles that are disadvantageous and to the factors that, conversely, favor adherence and persistence.

Objectives: to fix the degree of adherence to therapy - with DMARDs and biological indifferently - in the three different pathologies; to identify obstacles and factors predisposing good adherence and persistence by patients; to compare the three different populations, highlighting similarities and significant differences Methods: a 72 questions questionnaire - about $50 \%$ of which were dedicated to adherence and persistence to therapy and the predisposing factors and impediments - prepared in collaboration with Doxapharma was administered to patients with RMDS, IBD, PSO via web and by volunteers of the three associations. The evaluation of adherence to therapy ("degree in which a person's behavior in taking medication, following a diet and/or change the lifestyle, corresponds to the specific recommendations made in agreement with the Medical") was assessed by Morisky Medication Adherence Scale - 8 items (MMAS-8)

Results: 1.017 patients - 233 with RMDs (AR e SA), 449 with IBD (Crohn and ulcerative colitis), 273 with PSO and 62 APs -answered to the questionnaire useful for the purpose of the study.

Non-adherence varies in a range from $50 \%$ of dermatological patients, to $44 \%$ of them with IBDs, to $40 \%$ of patients with APs, to $36 \%$ of them with RMDs. Only $74.8 \%$ of adherent people is persistent $(83 \%$ in biologic therapy; $76 \%$ in DMARDS) and non-persistent patients does not ask and/or inform their doctors.

Patients with Psoriasis take therapies more discontinuously and inaccurately then all the others.

Promote adherence:

- good support from doctors and health professionals

- satisfaciton with information received

- the best QOL

- easiness and lack of problems in taking drugs

- satisfaction with the therapy

- biologic therapies (even for the best QoL ensured)

Promote discontinuity and non-adherence:

- dissatisfaction with the relationship with doctors and health professionals $(33 \%$ $\div 70 \%$ of patients is dissatisfied)

Conclusions: Our study shows that patients who enjoy a better health state, both physically and psychologically, are more likely to follow the treatment prescribed by their doctor, according to the mode and the specified time, especially if properly informed and well supported in choices, shared by medical and health professional staff.

Disclosure of Interest: None declared

DOI: 10.1136/annrheumdis-2017-eular.3102 